\title{
The Use of Gold in Dentistry
}

\author{
AN HISTORICAL OVERVIEW. PART II
}

\author{
J. A. Donaldson \\ British Dental Association Museum, London, U.K.
}

\begin{abstract}
Much is to be learned about the use of gold in connection with artificial teeth during the eighteenth century, from the works of French dentists. In 1699, a law was passed in France which limited the practice of dentistry to persons who had received specific training. Although the provisions of the law could be avoided without difficulty, its implementation led to a need for education in dentistry and for text-books. It was this need that stimulated Pierre Fauchard (8) to produce 'Le Chirurgien Dentiste', in which he displayed a much more scientific attitude than any previous dental author. Moreover, it is clear from the text that he wrote from extensive clinical experience.

Fauchard's book describes the use of ox bones and of teeth from humans, hippopotami, sea-horses or oxen for the construction of dentures and the use of gold wire, bands and springs to attach these to neighbouring teeth or to press them into place. Advice is given on the assembly of suitable natural teeth to fill a space and how to mount them in front of a strip of gold by means of rivets. Although Fauchard does not mention the use of gold bases for dentures, he devotes chapters to the construction of obturators to cover or block defects of the palate, for which such bases were also used.
\end{abstract}

Fauchard, and other eighteenth century dentists who discussed dentures, gave very little detail of how they worked or shaped that surface of the prosthesis that fitted or rested against the soft tissue of the mouth and it is not possible from the information given to attempt confidently to reconstruct their methods. It has been suggested that dentists of the period relied on measurements taken with such calipers or dividers as were used by sculptors and that they may have worked freehand and in reverse from a wax impression of the mouth, or of that part of it that the denture had to fit. Matthäus Gottfried Purmann, a seventeenth century German surgeon, has been credited with taking wax impressions, but it seems more likely that he made freehand models of the jaw in wax and fitted his artificial substitutes to them (23). It was Philipp Pfaff (24) who first suggested in 1756 the use of a (positive) plaster of Paris model, made from a (negative) impression of the mouth taken in what he describes as 'sealing wax' previously softened in hot water. Once the idea of making a hard and accurate model from an impression had begun to cir- culate, the way was open for the development of methods to improve the accuracy of the fit of dentures and for the use of gold plates as denture bases.

\section{Gold as the Denture Base}

In his 'Recherches et Observations sur Toutes les Parties de l'Art du Dentiste' of 1757, Etienne Bourdet (25) described and illustrated an artificial denture with a gold base which was enamelled to conceal its conspicuous colour. Commenting on this, HoffmannAxthelm (23) pointed out that Bourdet's goldsmith worked from a negative wax impression (modèle en cire) after the manner that Purmann had already suggested in the seventeenth century and that Pfaff's positive model method, although contemporary with Bourdet's work, remained unknown in Paris for some decades.

Following this, a number of authors, including Delabarre (26) referred to, and in some cases i1lustrated, more or less similarly contructed dentures with gold bases, but not one gives sufficient detail to make it possible to understand exactly how the metal was struck or otherwise worked to the shape required. However, by the time Delabarre's handbook was published in 1820, or a little later, someone had conceived the idea of making a negative impression in fine foundry sand of a positive plaster model of a mouth and pouring a positive model of lead or some other metal which was then used as a die for striking of the gold plate. The next advance was to cast the model or die in zinc, to cast a counter-die to it in lead and to swage the gold plate between the die and its counter-die.

The British Dental Association Museum has in its possession a small swaged gold partial denture reputed to have been made by Isaac Wilson, a dentist who practised in Bath at the beginning of the nineteenth century for William, Duke of Clarence. However, this one item cannot be regarded as more than circumstancial evidence that the method of swaging was used at the time. More certain evidence that the method was common by the late 1840's is derived from the workshop book of John Tomes, in which are recorded details of the dentures that he supplied to patients from 17 January, 1848, to 21 December, 1874, including the mass of gold in those that had gold bases, the number and types of teeth or 
Front and rear view of a swaged gold partial upper denture with carved ivory teeth, reputedly made for William, Duke of Clarence by Isaac Wilson of Bath (about 1810) Photograph by courtesy of the British Dental Association Museum, London

bone blocks, the types of clasps used and the name of the technician involved. This book is now kept at the British Dental Association Library, in London. The extreme secrecy prevailing between dentists in the early nineteenth century and the jealousy with which each guarded the details of his technique - disclosing it only to apprentices whose parents were frequently charged extortionate premiums - may go some way to explain the absence of contemporary records of the introduction of swaging for the working of gold. However, the organization of dental education and dental societies, in the U.S.A. in the early 1840's and in Britain in the 1850's, provided a need for textbooks and encouraged the exchange of knowledge and experience. Only then were the methods of casting dies and counter-dies and swaging gold plate with them written down, but the authors wrote about these techniques in a style that suggested that they were already widely used.

Swaging of gold plates as denture bases persisted for over a century. It was still being taught to dental students and they were still required to be able to pass a practical examination on it in Great Britain until the 1940's, although it had been gradually superseded by lost wax casting since 1907 when the new methods of Taggart, Solbrig and others became known. The processes involved in swaging gold plates - the sand moulding and casting of metal dies, the design of the plates and the stages of swaging them on a succession of dies, and the making and soldering of bands or fastenings - together with the tools needed and the organization of the workshop have been detailed by Pearsall (27) who wrote in the heyday of their use.

\section{Gold Crowns}

It has been suggested by some writers on dental history, including Weinberger (28), that gold shell

Swiged upper and lower gold dentures with porcelain anterior tube teeth fitted over posts soldered into the plates, with ivory posterior masticating surfaces and with gold springs to aid retention in the mouth (about 1865) Photograph by courtersy of the British Dental Association Museum, London
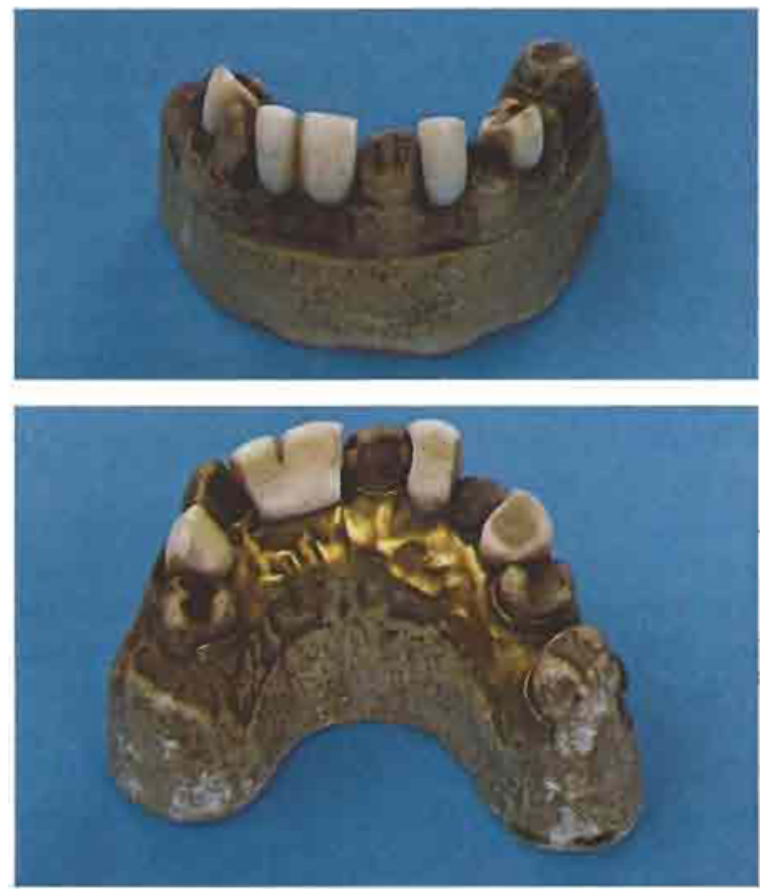

crowns were made and used in Roman times, but the assumption needs to be re-examined and re-evaluated as no specimen appears to be known.

The story of a sixteenth century hoax involving a gold crown is reliably supported, but it was a single occurrence and there is no indication that crowns were being made at that time for the treatment or protection of damaged teeth. A few days before Easter, 1593, a Silesian boy, seven years of age, was observed to have a tooth of gold. All the other teeth that should have been present at his age were there except for one adjacent to the gold tooth. News of the 'miracle' spread; examination showed that the tooth was indeed

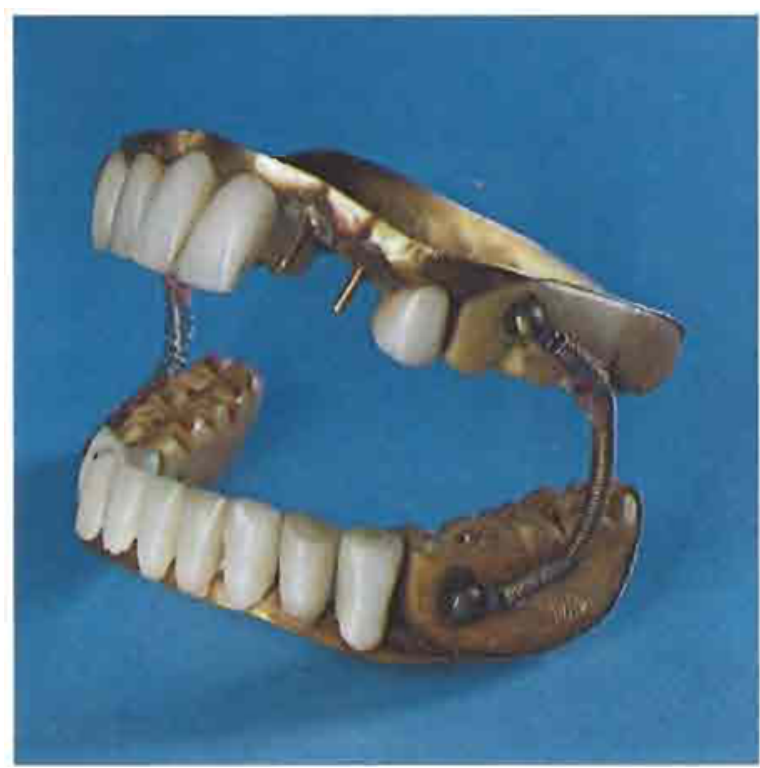


gold. Jacob Horst, professor of medicine at the Julius University of Helmstedt, investigated the case and sought to interpret its significance. In due course, he published a book about the case, calling it 'the world's greatest wonder' and stating that the golden tooth was created by some supernatural power at a moment of special astrological importance and deducing from the occurrence a number of omens and portents (29). In time, the stresses of biting and chewing wore through the gold and exposed the tooth substance beneath. The fake was discovered, and the unfortunate child went to prison.

Claude Mouton (10) was the first to describe in some detail the use of gold cap crowns for the repair of extensively decayed teeth, especially back teeth and, if they were far enough forward in the mouth to be seen, he recommended enamelling them as 'every eye would take offence at the loud colour'.

Toward the end of the nineteenth century and in the early twentieth century, a variety of techniques was developed for producing gold cap crowns. Seamless crowns could be made from $0.22 \mathrm{~mm}$ thick discs of 22 or 20 carat gold alloy drawn with a drawpress or by some method of swaging to make a 'blank' (or ready-made blanks could be used). The blanks were driven into a suitably shaped hollow mould with pine-wood punches and small pieces of hard rubber until the metal was adapted to it and the chewing surface was finally sealed and strengthened with gold

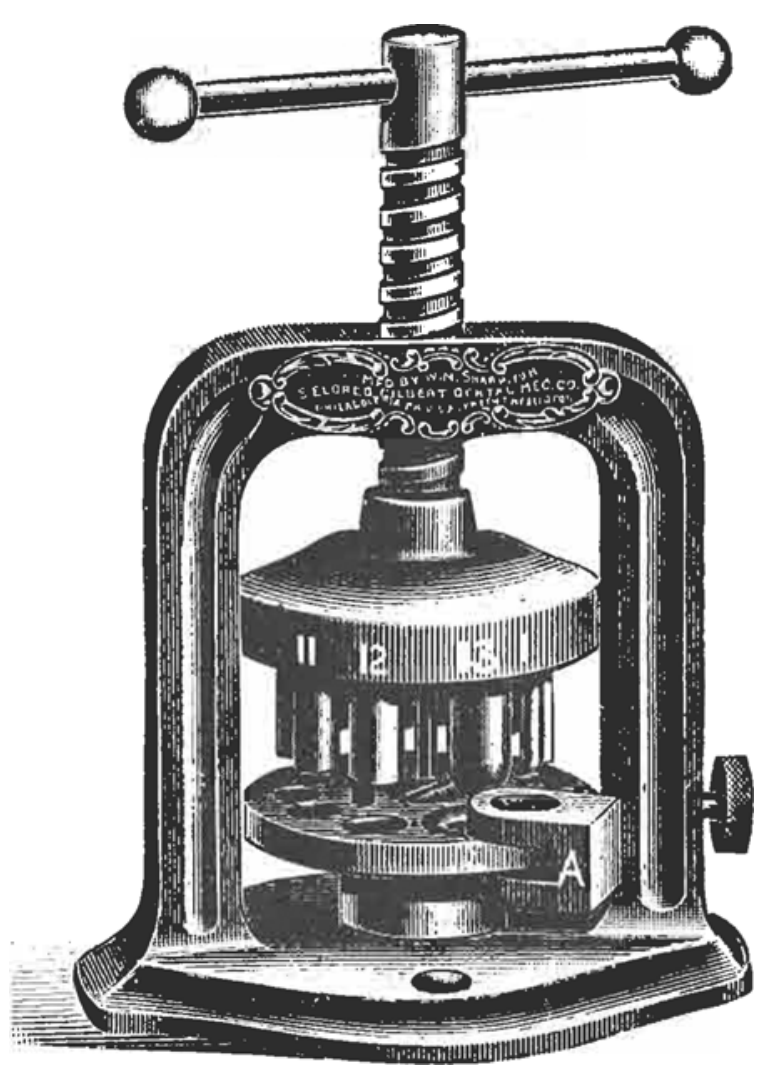

solder. To make the mould, either a rubber tooth of suitable size and shape, sold for the purpose, was chosen or a positive model of the tooth was made in plaster or clay from an impression. The rubber tooth or the model was fixed to a base, an iron ring was placed around it and low melting fusible metal was poured into the ring. When the metal had cooled, the mould was knocked out of the ring, split longitudinally to release the rubber tooth or model and the two halves were put together and forced back into the iron ring. Alternative methods included the cutting of a $0.22 \mathrm{~mm}$ thick strip of 20 or 22 carat gold alloy, long enough to form a band around the tooth, soldering the ends together, placing the band around the tooth (or a model made from an impression) and shaping a wax pattern of the appropriate chewing surface. The wax pattern was then cast in gold by the lost wax process and this casting was soldered to the band.

All these early methods that relied on swaged blanks or manipulated bands were open to the objection that a high proportion of the crowns so made were liable under the stresses of mastication to develop leaks, often undetected until too late, around the periphery. These permitted seepage of oral fluids and bacteria so that decay developed beneath the crown. However, the introduction in the last three or four decades of increasingly precise impression techniques using a succession of new materials, the electrodepositon of copper or silver inside the impression and the filling of the impression inside the electrodeposited lining with a hard plaster to produce an accurate copper- or silver-plated model has made it possible to cast gold crowns with correspondingly greater precision.

At least as early as the first half of the eighteenth century, post crowns, or 'pivots', were known as a means of restoring teeth of which the roots remained. Using these, a substitute or artificial crown was fixed to a wire post which is inserted into the pulp canal, and Fauchard (8) describes and illustrates the use of a natural human tooth retained by a gold post. A vast number of methods of constructing post crowns was introduced during the ensuing 250 years. Early in the nineteenth century, natural human teeth were replaced by teeth of porcelain in various forms. For instance, solid porcelain teeth were made with a central hole or tube that could be fitted over a post, and

Sharp's draw-press for making tubular blanks of predetermined size from 0.22 nun thick discs of gold to fit the circumference of a tooth. These blanks were then used to make cap crowns. The model dates to about 1900 
A standard set of Angle's orthodontic applianees, made of platinised gold, as shown in a catalogue dated 1899

porcelain facings were made with flat backs from which protruded platinum pins which could be soldered to gold backings and gold posts. Later, solid porcelain crowns were introduced with a blind recess into which a post known as a 'dowel' could be fitted. Gold posts for crowns could be fashioned from wire and often had a thin gold diaphragm soldered to them and swaged to seal off the end of the root canal. Ready-made posts were supplied to match some types of crown and posts could also be cast.

\section{Crowns as Bridge Abutments}

Most types of crown - cap or post - have been used as abutments to support fixed bridges that replace missing teeth. The so-called and widely advertised 'American dentistry' of the late nineteenth century, which made great use of bridges supported by multiple post crowns on pulpless teeth, fell into ill repute after the publication in 1911 by a physician of a paper attributing the cause of a wide variety of general diseases to 'septic foci' associated with such teeth. The then new, but rapidly developing, science of dental radiography supported the suggestion that septic foci were associated with 'dead' teeth and, in many cases, if a dark shadow was shown surrounding the apex of the root of such a tooth in a radiograph, the tooth was condemned to extraction. The introduction of lost wax casting of gold inlays in the same period, however, made possible the design and construction of bridges which were supported by cast inlays and crowns on live teeth which remained healthy for many years. Recently, with a much increased understanding of the treatment of pulpless teeth, as well as the development of very accurate methods of impression-taking and casting, there has been some return to the use of such teeth as bridge abutments.

\section{Precision Attachments}

Also in recent years, roots have been kept in the jaws, after appropriate treatment against sepsis, to serve as retainers for dentures in certain difficult cases. Into the prepared root canals are fitted readymade gold alloy posts which have a head so shaped that it will clip into, or otherwise stay firmly in, a hollow portion that is accurately located in the denture during its manufacture. The denture can be removed by its wearer for cleaning and replaced by him. The 'precision attachments' help to keep it steady.

Another class of retainer or precision attachment which had its origin in the U.S.A. as long ago as the $1890^{\prime}$ 's, but in recent decades has become largely the
PATENTLD REGULATING APITINCTE.

(Dn. E. H. ANGTE'S.)

SET No. 1 .

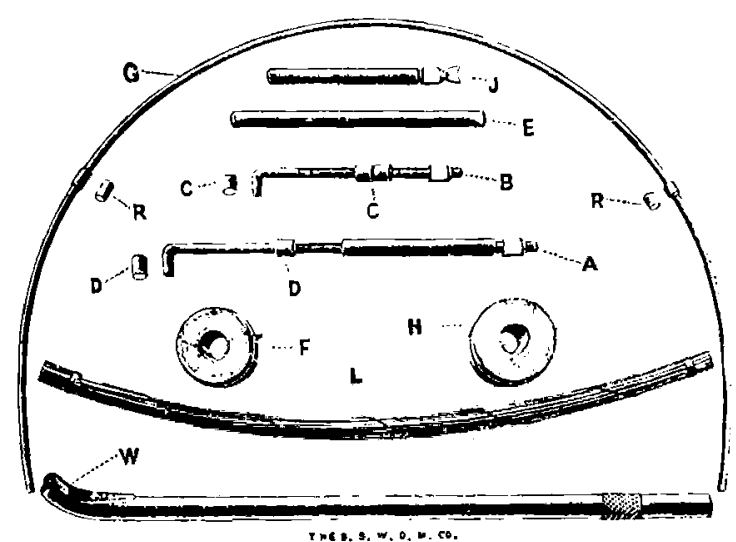

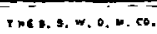

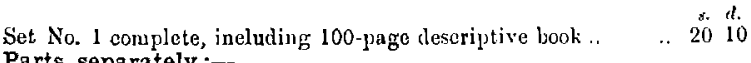
Parts separately:-

'I'raction Scrow, $A$ and $D$

J 13 and $C$

Jack-Screw, $E$ and $y$

Coils of Band Material, $\ddot{F}$ ancl $\ddot{l l}$

Retaining Wire, $G$

Rotating Levers, $I$

Retaining Pipes, $h$

I'rench, W

EXTRA PARTS

ADJLSTABLF CLAHE BANDS FOR BICUSPIDS AND MOLARS.

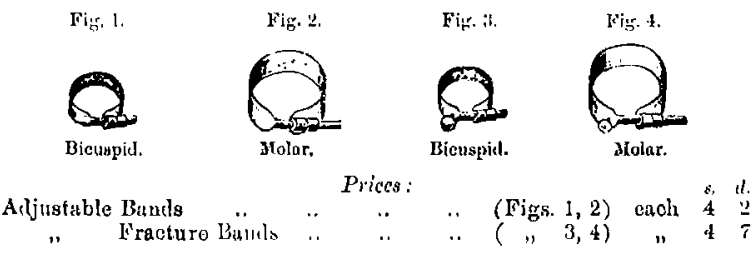

specialty of Swiss firms that work precious metals, consists of pairs of male and female portions that can be embodied respectively in bridges of partial dentures and in gold inlays in selected abutment teeth. The advantages of these very expensive techniques are chiefly hygienic, as the prostheses can be removed for cleaning and care of the adjacent oral tissues and then replaced by the wearer.

\section{Gold in Orthodontics}

An account of the development of the use of gold in dentistry would be incomplete without some reference to the applications of the metal and its alloys in orthodontics, the specialty concerned with the correction of faults in the regularity and, therefore, function and appearance of the teeth.

Fauchard (8) is credited with describing the first orthodontic appliance which was variously named the 'bandeau', 'bandelette' or 'band'. A strip of precious metal, silver or gold, which he stated should be neither too stiff nor too flexible, of a width less than the height of the teeth, was bent to the regular arch that the teeth should follow and placed behind them. 
Holes were drilled at appropriate places, through which wires could be passed and tied to the teeth; by tightening from time to time the wires around the irregular, displaced teeth, they were drawn into line with the arch. Bourdet (25) illustrated an appliance similar to and probably derived from Fauchard's, which was shaped more accurately to fit against the molars and he specified that gold should be used to manufacture the device, as silver blackens in the mouth. Delabarre (30) invented a number of improvements in orthodontics, including the use of a gold band for better anchorage of a device intended to move displaced teeth, gold caps and a lever to rotate teeth, and the extension as far as the back teeth of a shaped strip of gold for the expansion of the arch of the teeth.

The establishment in 1839 of the first dental journal, The American Fournal of Dental Science, and a year later of the first dental school, the Baltimore College of Dental Surgery, and of the American Society of Dental Surgeons, stimulated the exchange of professional knowledge among dentists in the U.S.A. and there was considerable discussion of orthodontics. However, although gold is mentioned by some as a component of appliances, the lack of illustrations in early dental journals makes it difficult to ascertain their designs or to determine to whom priority for particular ideas should be attributed. The introduction of vulcanite to prosthetic dentistry led to its use for orthodontic plates and Tomes described the use of a vulcanite plate with a gold wire bow around the outer surfaces of the teeth, which could be adjusted by a nut.

The art of orthodontics developed in the U.S.A. during the second half of the nineteenth century at the hands of many dentists, until by the turn of the century a large variety of appliances, fixed or removable and very often of empirical rather than scientific design, was in use. Most removable appliances relied on the use of tinned piano wire springs in vulcanite bases. The fixed appliances used German silver anchor bands fixed around molar teeth by screw clamps and connected by 'arch' wires of German silver that passed around the front of the teeth. These arch wires were tensioned so as to move displaced teeth directly or had spurs or hooks soft-soldered to them, from which small rubber bands provided means to move the teeth. The replacement during this period of German silver by alloys of gold and platinum with small quantities of other metals, for both the bands and for the arch wires and their attachments, led to an enormous advance in the effectiveness with which the teeth of children could be moved. These alloys were specially formulated by precious metal refiners and dealers to have high melting ranges so that component parts could be united by hard solder. Other properties improved by skilful gold alloy formulation included stiffness, so that the alloys could be manipulated to form springs or other devices of predictable performance, response to heat treatment to restore stiffness after hardsoldering and response to annealing to facilitate manipulation.

At a time when there was a great diversity of orthodontic techniques, with many practitioners empirically designing individual fixed appliances of varying degrees of complexity for each patient, E.H. Angle (31) introduced a single appliance which he held as capable of adaptation to bring about most of the desired tooth movements. This, he developed on the basis of a simple observation of the normal relationship between upper and lower first molar teeth. The appliance was patented in due course and was supplied in sets comprising coils of band material

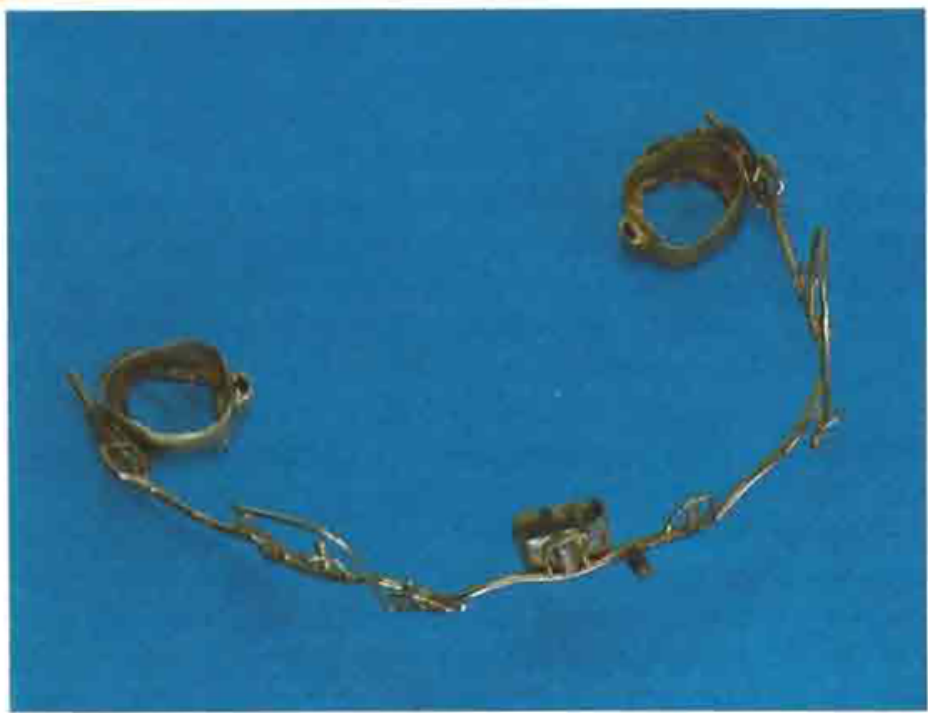

An orthodontic fixed appliance for the upper teeth made from gold and platinum alloys. In spite of about thirty gold-soldered joints in its construction, it retained adequate resilience to impart the appropriate gentle stresses to the teeth to be moved

Photograph by courtesy of Mr Herbert E. Wilson 
(or ready-made bands to clamp around molar teeth), arch wire, threaded rods of various forms with nuts, tubes for attachment to the bands with solder and wires for 'levers', all made from gold alloys. Together with these, came a copy of a handbook, "The Angle System of Regulation and Retention of the Teeth'. The use of this simplified and standardized system, as well as Angle's classification of malocclusion - first published in 1899 and to which his system was related - spread throughout the world, the handbook being translated into many languages. Angle's classification is widely used to this day, although research into the development of the jaws has shown that processes of growth and movement are not as simple as he believed, and many features of his appliances, including some that he borrowed from his predecessors and modified, are incorporated in the most modern fixed appliance orthodontics.

For many years, Angle's appliances, and others made from gold alloys which soon followed them, were obtainable only from the U.S.A., but in 1912, Sheldon Friel, of Dublin, who had some years earlier completed a course at the postgraduate school that Angle had established, was instrumental in having platinized gold band material, wires, tubes and other accessories for fixed appliance orthodontics made in London by Messrs. Johnson, Matthey \& Co., Limited. In 1933, Friel and McKeag introduced the use of spot-welded stainless steel fixed appliances. In Great Britain, partly owing to the increasing cost of gold and other economic factors, and partly owing to the exploitation of physical properties of stainless steel not possessed by gold alloys, stainless steel has almost entirely replaced gold. In the U.S.A., however, stainless steel has not been adopted so widely.
These notes on the history of the use of gold in dentistry are not exhaustive and the contributions of many individuals have been omitted, but they have been planned to indicate the application in various fields of dentistry that have been found for gold and its alloys, and the main lines of their development. Very significant advances have been made by bullion refiners and dealers during the past 60 to 70 years which have assisted the scientific progress of the dentist's care of his patient. Thus, the formulation of materials of accurately predictable physical properties for special purposes culminated about 20 years ago in the introduction of gold-based alloys onto which porcelain can be directly fired without subsequent fracture occurring because of differences in thermal expansion coefficients. However, that is another facet in the history of the use of gold in dentistry which is worthy of study, but it would have been extravagent of space to include it here.

\section{References}

23 W. Hoffman-Axthelm, 'Die Geschichte der Zahnheilkunde', Verlag Die Quintessenz, Berlin, 1973

24. P. Pfaff, 'Abhandlung von den Zähnen', Haude und Spener, Berlin, 1756

25 E. Bourdet, 'Recherches et Observations sur T'outes les Parties de l'Art du Dentiste', J.T. Herissant, Paris, 1757

26 D. F. Delabarre, 'Traité de la Partie Mécanique de l' Art du Chirurgien-Dentiste', Paris, 1820

27 W. B. Pearsall, 'Mechanical Practice in Dentistry', Claudius Ash \& Sons, London, 1898

28 B. W. Weinberger, 'An Introduction to the History of Dentistry', Mosby, St. Louis, 1948

29 J. Horst, 'De Aureo Dente Maxillari Pueri Silesii', Leipzig, 1595

30 C. F. Delabarre, 'Traité de la Seconde Dentition et Méthode Naturelle de la Diriger; Suivis d'un Apercu de Séméiotique Buccale', Paris, 1819

31 E. H. Angle, 'Notes on Orthodontia with a New System of Regulation and Retention', Dent. Cosmos, 1887, 29, 757-763

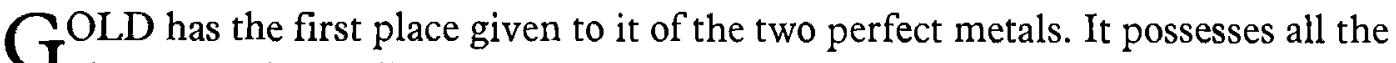
characteristic qualities of metals in a plenary degree; and joins to them a specific gravity greater than that of any metallic body or other body hitherto known. It is of full yellow colour, and is liquified by the degree of heat which brings it to a state of luminous whiteness; but it nevertheless remains without change in that or any other degree of heat producible by culinary fire for the greatest length of time in which it has been hitherto continued in such a state.

London, 1759

ROBERT DOSSIE

Institutes of Experimental Chemistry 